\title{
Paulo Freire e o ser humano em processo de formação permanente
}

\author{
Paulo Freire and the human being in the permanent training process \\ Paulo Freire y el ser humano en proceso de formación permanente
}

DEMÉTRIO DELIZOICOV

Universidade Federal de Santa Catarina, Florianópolis- SC, Brasil.

NADIR CASTILHO DELIZOICOV

Universidade Comunitária da Região de Chapecó, Chapecó- SC, Brasil.

\section{ANTONIO FERNANDO GOUVÊA DA SILVA ${ }^{* * * *}$}

Universidade Federal de São Carlos, Sorocaba- SP, Brasil.

\begin{abstract}
RESUMO: Neste trabalho, apresentam-se aspectos da ontologia e da gnosiologia que fundamentam a concepção de formação permanente em Paulo Freire. Por meio do resgate de publicações, foca-se a ocorrência de ações formativas embasadas nessa perspectiva conceitual implementadas em redes públicas de ensino que adotaram premissas freireanas para a construção de currículos escolares. São caracterizados os denominados Movimentos de Reorientação Curricular, destacando-se a sua função como organizadores de práxis educativas direcionadoras à formação permanente de educadores numa perspectiva ético-crítica.
\end{abstract}

Palauras-chave: Formação permanente de educadores. Movimento de Reorientação Curricular. Concepção freireana em redes públicas de ensino.

* É doutor em Educação pela Universidade de São Paulo e professor da Universidade Federa de Santa Catarina. E-mail:<demetrio.neto@ufsc.br>.

* É doutora em Educação pela Universidade Federal de Santa Catarina e professora aposentada da Secretaria de Educação do Estado de São Paulo. Atualmente é docente na Universidade Comunitária da Região de Chapecó. E-mail: <ridanc.nadir@gmail.com>.

*** É doutor em Educação pela Pontifícia Universidade Católica de São Paulo. Atualmente é professor associado da Universidade Federa de São Carlos (campus Sorocaba).E-mail:<gova@uol.com.br>. 
ABSTRACT: Aspects of ontology and gnoseology underlining the concept of permanent training have been presented in this work. Through the rescue of publications, it focuses on the occurrence of training actions based on this conceptual perspective implemented in public education systems, which have adopted Freirean premises for the construction of school curriculum. The commonly named Curricular Reorientation Movements have been characterized, having their roles highlighted as organizers of educational praxis leading to permanent teacher training in an ethical-critical perspective.

Keywords: Permanent teacher training. Curricular Reorientation Movement. Freirean concepts in the public education system.

RESUMEN: En este trabajo se presentan aspectos de ontología y gnosiología que subyacen al concepto de formación permanente en Paulo Freire. A través del rescate de publicaciones se focaliza la ocurrencia de acciones formativas basadas en esta perspectiva conceptual, implementadas en redes de educación pública que adoptaron premisas freireanas para la construcción de currículos escolares. Se caracterizan los denominados Movimientos de Reorientación Curricular, destacando su papel como organizadores de praxis educativas que orientan la formación permanente de los educadores en una perspectiva ético-crítica.

Palabras clave: Educación permanente de educadores. Movimiento de reorientación curricular. Concepción freireana en las escuelas públicas.

\section{Introdução}

contextualização da concepção de educação de Paulo Freire em redes públi-
cas de ensino se iniciou, no Brasil, quando o educador assumiu a Secretaria de
Educação do Município de São Paulo (SME-SP), em 1989 (FREIRE, 1995). Fundamental para a sua implementação foram as iniciativas da SME-SP, durante o período 1989-1992, relativas à formação permanente de educadores da rede, conforme documentado, por exemplo, em Torres, Cadiz e Wong (2002); Brasil (1994); Pontuschka (1993) e Saul (1993).

Desdobramentos dessa iniciativa pioneira em outros municípios localizados em vários estados brasileiros de, praticamente, todas as regiões, têm sido registrados em diversas publicações, tais como Delizoicov, N., Stuani e Delizoicov (2013); Saul (2012); Saul e Silva (2009); Delizoicov (2008) e Silva (2004), que exploram distintos aspectos do legado 
freireano em sistemas públicos de educação. Muitos gestores públicos vêm direcionando ações educativas, nas suas respectivas redes de ensino, tendo como principais referências os processos ocorridos no município de São Paulo entre 1989 e 1992.

A implementação dessas propostas envolve, pelo menos: 1) a formulação de novas opções para a gestão financeira das redes públicas (CAMARGO, 1997; BR ASIL, 1994); 2) a implantação de uma reorganização administrativa (SILVA, 2004; TORRES; CADIZ; WONG, 2002; CAMARGO, 1997; BRASIL,1994) para orientação pedagógica que assegure a sintonia com as premissas freireanas; 3 ) uma readequação do cotidiano escolar (PERNAMBUCO, 1994) e 4) a adoção de parâmetros distintos (SAUL, 2010; SILVA, 2002; SAUL, 1998; SILVA, 1996; BRASIL, 1994) dos que historicamente têm direcionado a construção curricular.

Não obstante essas demandas, o presente artigo tem como foco destacar aspectos relacionados à formação permanente dos educadores de redes públicas de ensino que, de fato, dependem dos quatro processos apresentados. A formação permanente nas redes públicas que se organizaram para efetivá-la na perspectiva freireana ocorreu, dentre outras iniciativas, através de ações coordenadas pelo que se denominou Movimento de Reorientação Curricular, cujos aspectos fundamentais serão resenhados nos dois últimos itens deste artigo. Antes disso, passamos à exposição do se entende por formação permanente na base conceitual aqui assumida.

\section{Formação permanente e as concepções ontológica e gnosiológica}

O significado da formação permanente em Freire é consequência tanto da sua concepção ontológica de ser humano, como da gnosiológica que sustenta sua argumentação sobre a produção de conhecimento. Dentro dela está a produção cultural do ser humano, em qualquer e nas mais distintas atividades às quais se dedica para criar cultura e interagir com ela. Nesse sentido, o processo educativo escolar é concebido, também, como um dos elementos constituintes da formação permanente de estudantes, não apenas de seu professorado. Ambos, para Freire, têm uma natureza inconclusa, que depende, essencialmente, das interações socioculturais que ocorrem em contextos espaço-temporais, tendo, portanto, uma história vinculada a espaços geográficos. Daí que, tanto o professorado como o alunato, ou o educador e o educando, como designa Freire, constituem-se, na compreensão freireana, através de uma formação (cultural) permanente, no sentido de que sua humanização tem relação intrínseca com o conhecimento ainda porvir para cada um deles, que estão vivendo num determinado tempo, em contextos marcados por suas especificidades históricas e geográficos. Desse modo, Freire articula sua concepção ontológica, segundo a qual o ser humano é inconcluso, com sua concepção gnosiológica, 
na qual o conhecimento é porvir, para estabelecer especificidades das relações entre educador e educando como um devir das ações educativas.

Há uma relativa clareza segundo a qual as teorias formuladas por seres humanos - a respeito tanto de fenômenos naturais como dos econômicos e socioculturais por eles construídos - possuem uma história que anuncia suas mudanças ou mesmo sua superação. Tais teorias são parte das referências para a constituição de programas de ensino na educação escolar. Não obstante, as transformações que ocorrem com essas teorias, suas explicações e modelos interpretativos nem sempre são consideradas devidamente em análises gnosiológicas, com reflexos em processos educacionais de todos os níveis de ensino. A compreensão das transformações históricas quer naturais, quer construídas por nós, depende, dentre outros fatores, da particular filiação filosófica que fundamenta as distintas e, algumas vezes, incompatíveis análises. A análise que Freire faz dessas questões está apresentada em vários dos seus livros.

A compreensão gnosiológica que Freire apresenta é densamente argumentada ao destacar que o conhecimento é porvir, ou seja, assume uma concepção segundo a qual é possível haver conhecimento sobre as coisas, contudo, amanhã saberemos mais do que hoje, numa interpretação livre do que seria um conhecimento porvir. Em outros termos, afina-se com uma concepção crítica sobre a possibilidade de conhecer, conforme seria categorizada do ponto de vista filosófico a teoria do conhecimento (gnosiologia) que Freire sustenta. Aprofunda, também, sua argumentação a respeito da ontologia do sujeito, ou seja, o ser humano que deseja conhecer é concebido como um sujeito que se constitui na sua relação com os outros, com o mundo natural e com o construído pelos seres humanos. Essa característica, conforme argumenta Freire, é que nos torna inconclusos. Na medida em que estabelece suas relações socioculturais e com o mundo existente, o ser humano pode vir a ser mais, desde que possa compreender e fazer, em um dado momento da sua história, o que não compreendia e nem fazia anteriormente. É a esse ser mais que Freire concebe como humanização do ser humano, enquanto finalidade da espécie Homo sapiens.

A produção cultural, portanto, que inclui as explicações do mundo e as relações que se estabelecem com ele, é determinante para a humanização. Contudo, essas explicações têm uma temporalidade, assim como uma espacialidade que, na perspectiva gnosiológica freireana, são passíveis de transformações que implicam no amanhã conhecermos mais do que hoje. Assim, por exemplo, os denominados cientistas, não importa de qual área de atuação, quando compreendem algo inédito, realizam o desiderato da humanização. É o novo, por eles concebido, que se transforma em conhecimentos históricos e tidos como universais, considerando a característica do devir. Não obstante, há outros conhecimentos oriundos de determinado tempo e espaço que, mesmo ainda não universalizados, por terem a sua historicidade e a sua espacialidade, parametrizam as relações socioculturais que constituem o ser humano para se relacionar com o mundo no qual está vivendo. As línguas faladas, do mesmo modo que sua escrita, quando se efetivam, 
ambas como devir, são exemplos dessa característica espaço-temporal da cultura produzida. Freire, ao explicitar esse aspecto, além de valorizar a produção cultural de qualquer ser humano, destaca, ao propor um quefazer educativo, o papel da dialogicidade a ser implementada entre os conhecimentos humanos que possuem suas histórias e ocorrem em distintos espaços por eles habitados.

É a intenção de Freire que o processo educativo contribua para uma Educação como prática de liberdade e possibilite uma Pedagogia do oprimido, conforme aborda nos livros com esses títulos.

No primeiro (FREIRE, 1968), como decorrência de uma práxis educativa que vinha construindo desde a segunda metade do século $X X$, o autor se dedica a analisar a implementação de ações no âmbito da alfabetização de adultos, considerando a contribuição delas para a constituição do analfabeto a caminho de um ser mais. Explicita as relações entre a sua concepção de ser humano inconcluso com a necessidade de ações educativas consequentes, cuja intencionalidade esteja em promover o desiderato do ser mais.

É fundamental destacar alguns aspectos que envolvem a contradição implicada no analfabetismo. Assim, temos: 1) mais de 5.000 anos decorridos da invenção da escrita e dos diversos alfabetos, pelo Homo sapiens; 2) a invenção da imprensa com caracteres móveis de metal no século XV, com a consequente possibilidade de livros impressos; e 3) uma educação escolar, a partir do século XVII, destinada não só a formar a aristocracia e religiosos, principalmente na Europa, mas também para sujeitos oriundos de outras camadas sociais. Não obstante isso, ainda hoje, em pleno século XXI, existem seres humanos analfabetos. Esse é um exemplo no qual se destaca que o processo de humanização envolvido nessas atividades não estaria sendo compartilhado por todos os membros da espécie. Representa, portanto, uma contradição cujos impactos têm distintas incidências, dependendo dos contextos espaço-temporais em que ela ocorre. Fundamental, para Freire, é desvelar as manifestações locais e a história delas, nas especificidades em que se dará a ação alfabetizadora. É a identificação dessas manifestações locais a matéria-prima com a qual se realiza o planejamento educativo. A intenção é que, ao ir sendo alfabetizado, o ser humano também possa ir compreendendo a situação na qual se encontra. Freire aprofunda a contribuição que atos educativos pautados pela dialogicidade podem oferecer para essa compreensão de seres humanos não alfabetizados. O processo educativo, portanto, ao ter como um fator determinante a compreensão, pelo próprio ser humano analfabeto, dessa contradição histórica, teria, conforme argumenta Freire, a contribuir para que ele atuasse, junto com outros, para transformar as condições que limitam sua promoção ao ser mais.

Já no segundo livro (FREIRE, 1975), devido à participação do autor, no Chile, em processos educativos pós-alfabetização de camponeses, encontra-se o aprofundamento da função de uma educação que visa o ser mais. Assim, não basta que o ser humano, ao se humanizar, domine a leitura e a escrita de alguma língua. Deverá haver critérios através dos quais se possa selecionar conhecimentos para a compreensão de outras contradições 
que, historicamente, também ocasionam um não compartilhamento de outros processos, que, ao longo da História do Homo sapiens, possibilitaram galgar degraus humanizadores. Freire (1975) apresenta uma argumentação segundo a qual a educação teria uma contribuição a dar para a constituição do ser mais, através de processos educativos que incluam a compreensão dessas contradições.

Em Extensão ou Comunicação? (FREIRE, 1977), o autor se dedica, especialmente, a aprofundar a ontologia do ser humano e a gnosiologia que sustenta suas considerações. Ele pretende estabelecer as relações existentes entre o ser humano, conforme o concebe, à sua capacidade de produzir conhecimento e aos processos intencionalmente planejados, tais como atos educativos, no sentido da humanização. Com o desafio de estabelecer uma síntese dessas relações, Freire concebe a educação como uma situação gnosiológica, abordada no item com essa designação, no capítulo 3 do livro (FREIRE, 1977). Para analisar esse desafio, Freire articula a característica humana de se constituir em comunicação com os outros, ou seja, a dialogicidade com a gênese do conhecimento, que, em sintonia com outros filósofos e epistemólogos, é admitida como a busca de solução para problemas enfrentados por seres humanos que desejam e se empenham em resolvê-los. Nessa obra, ele dedica especial atenção aos problemas enfrentados pelo ser humano para se humanizar. Daí a origem do termo educação dialógico-problematizadora, como muitas vezes é referida a concepção educacional de Freire. Ele pretende que a educação dê a sua contribuição para uma formação permanente dos seres humanos. No caso da educação escolar, todos aqueles que com ela se relacionam: educandos, educadores e responsáveis pela gestão educacional.

Contudo, essa classe de problemas a que Freire se refere - os que são enfrentados para que o ser humano seja um vir a ser mais humano - tem determinadas características que impõem uma perspectiva ético-crítica (DUSSEL, 2000). Essa opção tem reflexos na compreensão curricular cuja construção implica a formação permanente do professorado e demais profissionais atuantes nas redes de ensino.

\section{A práxis curricular como processo de formação permanente}

Para Freire (1975), a práxis transformadora autêntica é uma exigência ontológica para o ser mais. Nessa direção, questiona-se: que exigências curriculares esse compromisso traz para a constituição de uma formação docente humanizadora?

De forma sintética, podemos dizer que o autor defende uma sistematização curricular que prioriza uma práxis transformadora fundamentada em uma racionalidade crítica. A indissociabilidade entre a reflexão sobre a prática pedagógica, sua recriação e as transformações mútuas que ocorrem tanto nos fazeres curriculares quanto nos sujeitos que as realizam manifesta implicações dialéticas da prática docente. Também a 
escolha da realidade concreta, assumida como mediadora entre educadores e educandos, é considerada o objeto de estudo a ser problematizado e apreendido em sua totalidade sociocultural, a partir de uma metodologia dialógica, que corrobora a dinâmica curricular. O autor caracteriza em Pedagogia do Oprimido (FREIRE, 1975) o objeto de estudo como contido nas contradições relacionadas à realização do ser mais para a humanização. Ele denomina esse tipo de objeto de estudo de tema gerador, no sentido de que as manifestações locais dessas contradições, bem como sua compreensão, geram um quefazer educativo, desafiando os seres humanos nelas imersos. Para se detectar essas manifestações, bem como compreendê-las numa perspectiva ético-crítica, Freire (1975) propõe e fundamenta procedimentos sintetizados num processo por ele denominado de investigação temática, quando, então, buscam-se as manifestações das contradições no contexto de vida do qual o educando é originário. É a compreensão circunstanciada por educadores e por estudantes das contradições assim localizadas por uma equipe interdisciplinar que determina o currículo escolar, na articulação dialógico-problematizadora dos conhecimentos.

Cabe destacar que não é qualquer recorte da realidade que deve ser tomado para investigação. No projeto pedagógico humanizador, a opção é pela escolha de situações significativas que representam contradições sociais que oprimem a comunidade e ainda não são percebidas e compreendidas, sendo aceitas de forma apática e conformista. Busca-se, portanto, o desvelamento e a origem das situações reais que se apresentam como obstáculos para a realização plena dos sujeitos em seu projeto de ser mais, de construir uma vida coletiva digna e justa. Dessa forma, a práxis autêntica na construção curricular pode ser considerada um processo permanente e dialético de formação contínua e dialógica de educadores. Eles precisam estar envolvidos com a organização e o desenvolvimento de uma outra hegemonia educacional, aquela comprometida com a emancipação das camadas populares excluídas, a partir de uma política curricular crítica e participativa. Daí a relevância de se considerar a dimensão ético-crítica da proposta curricular freireana (DUSSEL, 2000).

Como exigência ético-crítica para essa formação permanente dos educadores, é necessária a adoção de uma epistemologia de apercebimento e emancipação, constituída a partir do enfrentamento reflexivo dos educadores sobre os limites e contradições de suas práticas pedagógicas concretas. Essa opção demanda, necessariamente, problematizações que propiciem ao coletivo de docentes o distanciamento da rotina escolar, na perspectiva de apreendê-la de forma totalizadora para, então, municiados de criticidade, promoverem práticas curriculares inovadoras, superando alienações e construindo legitimidade. Este movimento coletivo de docentes e comunidade, ao explicitar seus conflitos pelo posicionamento epistemologicamente crítico de seus fazeres tácitos, possibilita a tomada de consciência da submissão dogmática à tradição curricular conservadora e pragmática, promovendo alternativas de recriação de práticas pedagógicas inovadoras, denominadas, muitas vezes, por secretarias de educação, como Movimentos de Reorientação ou Reestruturação Curricular (MRC). 
Sob a influência da práxis da gestão Paulo Freire (SME/SP, 1989-1992), durante os anos 90 do século passado e início dos anos 2000, vários municípios e estados brasileiros, comprometidos com a qualidade social da educação pública, desencadearam processos de formação permanente de educadores em movimentos coletivos de reorientação curricular. No sentido de fornecer referências documentais dessas políticas curriculares críticas articuladas aos processos formativos, destacamos alguns desses movimentos implementados por Secretarias de Educação de Prefeituras Municipais (PM/SME)) e de Secretarias Estaduais (SEE) que foram denominadas de "Administrações Populares".

Dentre os documentos publicados durante a gestão de Freire, destacam-se os seguintes cadernos formativos construídos por coletivos de educadores da rede de ensino de São Paulo, com assessores ligados a universidades: Temas geradores e construção do programa (PMSP/SME, 1991), Movimento de Reorientação Curricular: Caderno de Relatos de Práticas (PMSP/SME, 1992a) e Movimento Reorientação Curricular: Visão da Área (PMSP/SME, 1992b).

Tais publicações foram referência para a implementação de políticas educacionais, dentre outros, nos municípios de Angra dos Reis-RJ (1994-2000), Porto Alegre-RS (19952000), Chapecó-SC (1998-2003), Caxias do Sul-RS (1998-2003), Gravataí-RS (1997-1999), Vitória da Conquista-BA (1998 - 2000), Esteio-RS (1999-2003), Belém-PA (2000-2002), Maceió-AL (2000-2003), Dourados-MS (2001-2003), Goiânia-GO (2001-2003) e Criciúma-SC (2001-2003). Também subsidiaram ações como no processo Constituinte Escolar no Estado do Rio Grande do Sul (1998-2001) e na implementação da proposta curricular por ciclos de formação no Estado de Alagoas (2001-2003).

As sistematizações dos movimentos de reorientação curricular com caráter formativo podem ser consultadas em diversos documentos publicados pelas gestões das políticas públicas citadas. Pela abrangência dos documentos em relação à apresentação e desenvolvimento dos processos formativos, ressaltamos: Nova Qualidade do Ensino, Movimento de Reorientação Curricular de Angra dos Reis-RJ (PM/SME, documentos nº 1 e 2, 1995 e 1996); Plano Municipal de Educação: princípios gerais de Caxias do Sul-RS (PM/SMED, 1999); TrabaIhador fazendo história e a Revista Educação de Jovens e Adultos de Chapecó-SC (PM/SMEC, 1998 e 2001); Nossas práticas, nossa história, publicada em Criciúma-SC (PM/SME, PROEJA, 2003); Aprender é movimento de Esteio-RS (PM/SME, 2003); a publicação do caderno 1998: ano da reorientação curricular de Gravataí-RS (PM/SMEC, 1998); o documento Construindo a cidadania: uma experiência em processo de Maceió-AL (PM/SMED, DEJA, 2001); Escola cidadã: construindo sua identidade e A experiência da Escola Neuza Brizola na concretização da escola cidadã de Porto Alegre-RS (PM/SMED, 1995 e 1996) e Constituinte escolar: construção da escola democrática e popular do Estado do Rio Grande do Sul-RS (SEE, 2000).

Essas secretarias de educação buscaram modificar a prática educativa, adotando a escola como espaço de formação docente por excelência, desenvolvendo dinâmicas coletivas na abordagem dialética da reorientação curricular e de seu compromisso com as classes populares. Embora apresentassem princípios, diretrizes e métodos comuns, é 
importante salientar a variedade de práticas formativas observadas em cada administração, em função das especificidades locais.

Em relação à qualidade social do ensino, os movimentos de reorientação curricular e de gestão democrática manifestam-se pela pedagogia emancipatória, com o diálogo no trabalho coletivo envolvendo todos os segmentos escolares. Também se definem pela formação permanente dos educadores, tendo na práxis o processo de desconstrução/ reconstrução crítica da autonomia das unidades escolares.

Além do acesso à escola, é fundamental o desenvolvimento de um currículo comprometido com a permanência dos educandos. Assim, emancipação e autonomia são compreendidas como o reordenamento crítico dos sentidos e significados do fazer coletivo a partir dos limites da prática educacional conservadora vigente, propedêutica e anacrônica, fundamentada em uma racionalidade instrumental, promovida por currículos oficiais e livros didáticos. É a partir da apropriação de um conhecimento sistematizado, apreendido à luz de uma racionalidade problematizadora e crítica, que o processo de ensino-aprendizagem se faz promotor e emancipador da autonomia coletiva.

Em decorrência desse posicionamento epistemológico, a formação permanente no fazer curricular demanda uma abordagem interdisciplinar da realidade concreta para a organização de programações e práticas pedagógicas. Essa abordagem constitui-se como exigência para a construção de conhecimentos comprometidos com o desvelamento e a transformação do real vivenciado pela comunidade.

Destaca-se a importância de a formação permanente contar com a participação de equipes pedagógicas multidisciplinares, responsáveis pela coordenação da política curricular a ser desenvolvida nas unidades escolares das secretarias de educação. Concebidas como coletivos orgânicos aos processos formativos, as equipes pedagógicas que assessoram as escolas são as principais responsáveis pela qualidade da política curricular instituinte, que se concretiza na cotidianidade da práxis junto aos coletivos das comunidades escolares.

De forma sucinta, é possível evidenciar princípios ético-críticos e diretrizes político-epistemológicas que perpassam os processos de formação permanente a partir da práxis transformadora, em dinâmicas construtivas de currículos críticos. Silva (2004) sistematiza ações prioritárias para a democratização radical da escola que busca desenvolver tais políticas pedagógicas. Sinteticamente, enuncia:

Acesso e permanência da população na escola pública, ou seja, atendimento amplo nas diferentes modalidades e níveis de ensino, e viabilizar condições materiais ... o cidadão deve conceber a escola pública como um espaço institucional que busca atender às necessidades da comunidade;

Democratização da gestão da política educacional, ou seja instituir uma gestão colegiada que se efetiva em conselhos em diferentes instâncias de governo - secretarias, equipes pedagógicas, escolas -, e que, mais especificamente nas escolas, se concretiza com a organização de conselhos [deliberativos] ...; 
Implementação de políticas curriculares comprometidas com projetos político-pedagógicos que viabilizem a qualidade social da educação pública, promovendo a construção de movimentos de reorientação curricular concebidos como práxis coletivas de formação permanente de toda a comunidade escolar (SILVA, 2004, p. 298).

É no contexto das políticas curriculares comprometidas com a emancipação que a dimensão ético-crítica da formação permanente se consubstancia com a participação dos sujeitos coletivos, envolvidos em processos democráticos de gestão, que protagonizam a recriação da realidade escolar, superando, criticamente, obstáculos pedagógicos vigentes. A Figura 1, a seguir, procura sistematizar esse processo.

Figura 1: Representação das articulações entre políticas educacionais formativas

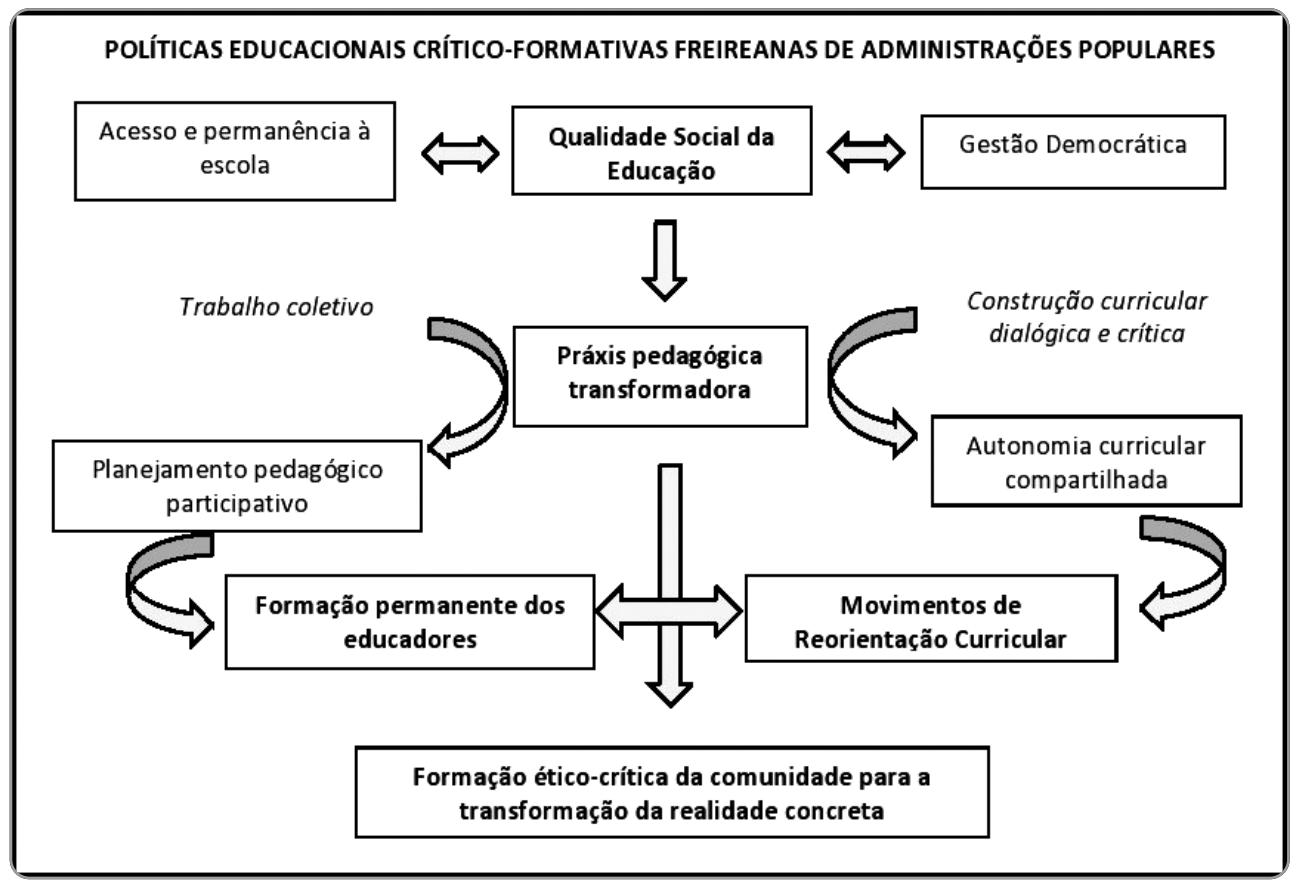

Fonte: Modificado a partir de Silva (2004).

Considerando esse contexto, trataremos das especificidades das propostas formativas embasadas na perspectiva freireana.

Formação Permanente em redes de ensino - objeto de investigação 
Com a denominação Movimento de Reorientação Curricular (MRC) instituiu-se parte das ações implementadas pelas secretarias de educação que possibilitaram a formação permanente das suas redes de ensino, de modo que as concepções educacionais de Freire pudessem ser orientadoras das práxis educativas em construção.

A literatura tem apontado distinções entre a concepção de formação continuada e a de formação permanente, tal como pode ser visto em Pinto (2015) e em Peixoto et al. (2013). Destacam-se não apenas as distintas ontologias e gnosiologias em processos destinados à formação de profissionais que já atuam em suas respectivas áreas, mas, sobretudo, o modus operandi que caracteriza cada uma dessas opções.

O processo de formação permanente que se concebeu em cada MRC teve a intenção de proporcionar a reorientação e a reestruturação das relações entre os membros da comunidade escolar numa dinâmica dialógico-problematizadora, em sintonia com a concepção de Freire. Uma premissa fundamental, resgatada pela pesquisa de Torres, Cadiz e Wong (2002, p. 81) a respeito da gestão de Freire na SME-SP (1989-1992), é que "as escolas devem ser não só um local de reconstrução crítica do conhecimento e de crítica da sociedade, mas também um centro de produção de cultura". Essa premissa exigiu a implementação de condições que impactaram o funcionamento do cotidiano escolar, bem como de mudanças na organização burocrático-pedagógica da SME, conforme analisado, por exemplo, em Pernambuco (1994) e Camargo (1997). Os estudos desses autores mostraram que houve a atribuição de carga horária aos educadores no espaço escolar destinado aos desafios da construção curricular. Essa dinâmica de trabalho docente nas escolas exigiu um aumento das verbas alocadas aos processos formativos (BRASIL, 1994). Com efeito, no MRC, as horas destinadas às discussões e estudos integravam a carga horária de trabalho dos educadores, uma vez que se trata de um processo coletivo, tendo a escola como o espaço para discussões, estudos destinados à reorientação curricular que eram assessorados por especialistas das SME e das universidades parceiras. Para tanto, "há uma alteração organizacional e funcional das escolas, o que depende de vontade política de gestores educacionais e do relativo aumento de recursos financeiros" (DELIZOICOV, 2008, p. 45, tradução nossa).

O ineditismo e a importância da formação permanente, como também a necessária organização das instâncias que a promovem para viabilizar esse processo, tendo a escola como espaço para a formação permanente, fazem com que se constituam em objetos de estudos de inúmeras investigações acadêmicas divulgadas em forma de teses, dissertações e artigos. Projeto de pesquisa coordenado por Saul (2012) que envolve pesquisadores de várias universidades brasileiras vem resgatando teses e dissertações que tiveram como foco a implementação por sistemas de ensino do pensamento de Paulo Freire. Trata-se de um projeto Interinstitucional da Cátedra Paulo Freire da PUC/SP, com cerca de dez anos, que investiga a influência da concepção freireana em redes públicas de educação e articula pesquisadores de várias regiões do País. Com o exame das teses e dissertações, 
estão sendo levantados dados, bem como realizadas análises sobre os distintos aspectos envolvidos nas práxis educativas oriundas dessas iniciativas.

Pretende-se com o desenrolar desse projeto elaborar um estado do conhecimento a respeito dessa produção. Partindo do princípio defendido por Freire (1993) de que na escola pública é possível fazer educação popular, Saul (2014) apresenta resultados de estudos que tiveram como objetivo investigar a materialização da práxis freireana na contemporaneidade e fornecem um amplo espectro do que vem ocorrendo nas escolas públicas. Saul (2016) apresenta resultados da segunda edição da pesquisa, desenvolvida no período 2012 a 2015. Os resultados indicam a atualidade das ideias de Paulo Freire nas políticas e práticas educativas em diferentes áreas do conhecimento.

Com objetivos mais limitados, neste artigo foram levantados alguns estudos que tiveram como foco analisar aspectos pontualmente relacionados aos MRC. Por um lado, eles possibilitaram alguma caracterização do que vem ocorrendo com a formação permanente coordenada por secretarias de educação que se basearam na práxis construída pela SME-SP, no período 1989-1992. Por outro, as referências aqui levantadas são apenas exemplares de estudos realizados, necessitando, portanto, de complementação. É importante enfatizar a existência de inúmeras outras investigações que tiveram como objeto de pesquisa o MRC implementado por várias secretarias que, não obstante, demandam um levantamento mais amplo das pesquisas com esse foco. A ampliação dos estudos sobre o MRC pode fornecer dados e análises de modo a se ter uma visão sistêmica do que vem ocorrendo com a formação permanente, o que não é objetivo deste artigo.

Apresentam-se, a seguir, exemplares localizados.

Em Delizoicov, N.; Stuani e Delizoicov, D. (2013) encontra-se a análise de dissertações das várias áreas do conhecimento, desenvolvidas em universidades localizadas na região Sul do País. A pesquisa considerou, nos trabalhos analisados, aspectos da implementação dos MRC em redes públicas e, ainda, quais obras de Paulo Freire subsidiaram esses estudos. Com base nos trabalhos, são apontados limites e possibilidades para implementações de MRC freireanas em redes públicas. Como desdobramento dessa pesquisa, um livro foi organizado (DELIZOICOV, N; STUANI; CUNHA, 2018).

Porto e Lima (2016) investigaram em teses e dissertações a contribuição das ideias de Freire para a formação de educadores. Com o levantamento, localizaram mais de uma centena de trabalhos. As autoras apresentam dados que indicam a forte presença de Freire na formação permanente.

A política e a prática da formação permanente da rede pública do município de Diadema, São Paulo, constituíram objeto de estudo de Vieira (2008). Entre outros resultados, a autora destacou a importância que educadores daquela rede de ensino atribuíram à reflexão sobre as práticas, bem como sobre o trabalho coletivo.

A formação permanente e sua implementação na rede pública de ensino de Caxias do Sul, no Governo da Administração Popular (1997-2004), constituiu o foco do trabalho 
desenvolvido por Giron (2007). Segundo a autora, uma das estratégias para a implantação dessa formação foi a reorganização do calendário escolar, de tal forma que os encontros pudessem ocorrer no horário de trabalho do professor. Giron (2007) aponta ainda que seminários, palestras, eventos por áreas do conhecimento e assessoria direta nas escolas, realizadas por especialistas, faziam parte do processo de formação permanente.

Contudo, o MRC que cada secretaria implementou depende de uma série de fatores, dentre eles o envolvimento dos educadores. Delizoicov (2008) assim sintetiza as relações do professorado com as pretensões da contextualização da perspectiva freireana por secretarias de educação:

[...] a implantação das proposições freireanas nas escolas, [...] não foi um processo homogêneo. Há uma heterogeneidade de comportamentos e compromissos [...] Há indicadores de que os professores, [...] podiam ser enquadrados, grosso modo, em três tendências, que poderíamos denominar de tendência aliada, tendência indiferente e tendência não-alinhada. [...] Uma das sinalizações para a coordenação do projeto quanto ao seu andamento é fornecida pelas manifestações e nível de adesão dos professores da tendência indiferente, de modo geral a maior representante. [...] Os professores da tendência aliada quase sempre se tornam também auxiliares no processo de coordenação .... Por outro lado, é preciso compreender que os professores da tendência não-alinhada, apesar de terem como característica essencial não se envolverem no projeto, têm distintos motivos para se manterem distantes. Por exemplo, aqueles que acreditam ter bons resultados com os alunos com o que já fazem, têm justificados argumentos para não mudar a prática docente, ou outros que por insegurança profissional também não se alinham. Diferentemente daqueles que, por razões ideológicas, não se envolvem ou mesmo se opõem às mudanças (DELIZOICOV, 2008, p. 45, tradução nossa).

Esta consideração do autor está presente em outros trabalhos consultados, a exemplo dos dois seguintes. No primeiro deles, Grosch (2011) analisa as políticas e os processos de formação ocorridos no período de 1997-2004, na Escola de Formação Permanente Paulo Freire, (EFPPF) da rede municipal de ensino de Blumenau (SC). O objetivo do estudo foi compreender as possibilidades dos educadores de construírem, numa perspectiva de teoria e prática, conhecimentos para a docência e a formação de um coletivo de educadores. Para a autora, destacam-se nesse movimento a carga horária semanal para estudos, o acesso e a permanência dos alunos na escola. No entanto, a Escola de Formação Permanente Paulo Freire teve seu fim, e a autora avalia que

[...] a atitude passiva, a falta de manifestação expressiva acerca dos avanços sinalizados pela existência desta escola de formação bem como a ausência de reivindicação de direitos conquistados representam indícios de fragilidade do coletivo, resistências, desconhecimento de parte dos professores sobre as concepções e conceitos que embasaram as políticas, evidenciando sentimentos de falta de pertencimento a uma classe (GROSCH, 2011, p. 18).

O processo de formação permanente implementado na educação de jovens e adultos (EJA) da rede pública de ensino do município de Chapecó, ocorrido entre os anos de 
1997 a 2004, foi objeto de análise por Cunha (2014) e Cunha e Delizoicov, N. (2016). As autoras consideram que, apesar de a formação possibilitar aos professores incorporar práticas freireanas no fazer docente, houve resistência por parte dos professores quanto às mudanças ocorridas no fazer pedagógico, à forma como os educandos eram avaliados e, ainda, quanto à forma como a proposta foi implantada pelos gestores.

Esses aspectos sugerem, mais do que alguma impossibilidade de contextualização da perspectiva freireana em redes públicas de ensino, a necessidade de considerá-la como um porvir, conforme o pressuposto gnosiológico freireano. É um processo intencionado de construção, o desafio a ser enfrentado para que haja um devir educacional que, atuando de modo problematizador com a materialidade das condições locais, implemente práticas educativas nas escolas em sintonia com uma educação ético-crítica. Afinal, após a publicação de Didactica Magna, por Comenius, em 1649, a educação escolar tem se transformado em múltiplos aspectos. Evidentemente, isso se dá com a contribuição das ações do professorado formado em sintonia com premissas transformadoras que vêm ocorrendo desde aquela época.

\section{Considerações finais}

A presença da concepção freireana da educação em redes públicas de ensino fundamental no Brasil possui uma história com cerca de 30 anos, que tem sido documentada e resgatada através de pesquisas. Mesmo assim, parece necessário intensificar a busca de dados relativos a essa história e analisá-los. Um exemplo de propostas nessa direção é o projeto coordenado por Saul (2012) que inclui pesquisas relativas aos MRC. Além disso, o projeto tem abrangência maior, na medida em que pretende incluir estudos sobre práxis educativas freireanas em redes de ensino, não obstante, agrega iniciativas de educadores que ocorrem independentemente de haver um projeto político-pedagógico da secretaria de educação e mesmo das escolas nas quais atuam.

Essas práxis parecem refletir um movimento de resistência a um ensino ainda não dialógico-problematizador. Elas se constituem como exemplares, tais como os incluídos em Watanabe (2019) e implementados no ensino médio, cujo resgate e análise pode contribuir para a construção de um ensino ético-crítico nas suas relações tanto com a formação dos docentes nas licenciaturas como com as que se constituirão em formações permanentes, organizadas e coordenadas por secretarias de educação. De modo semelhante, as práxis freireanas adotadas, ainda que pontualmente, durante a formação nas licenciaturas, a exemplo das que constituem o livro organizado por Molina (2017), também precisam, mais frequentemente, se tornar objetos de pesquisa. Certamente o resgate e análise dessas práxis no âmbito das licenciaturas têm muito a contribuir para que educadores possam vir a implementá-las enquanto profissionais que atuam na educação básica e também nos cursos de licenciatura. 
Recebido em 29/07/2020. Aprovado em 06/08/2020.

\section{Referências}

BRASIL (1994) Interdisciplinaridade no Município de São Paulo. Série Inovações Educacionais. Brasília: INEP/MEC.

CAMARGO, Rubens Barbosa de. Gestão democrática e a nova qualidade de ensino: o conselho de escola e o projeto da interdisciplinaridade nas escolas minicipais da cidade de São Paulo (1989-1992). Tese (doutorado) Programa de Pós-graduação em educação, Universidade de São Paulo, São Paulo, 1997.

CUNHA, Suzi Laura da. A Concepção freireana sobre a Formação Continuada de Professores: a EJA no Município de Chapecó. Dissertação (mestrado) - Programa de Pós-graduação em Educação, Unochapecó. Chapecó, 2014.

CUNHA, Suzi Laura da; DELIZOICOV, Nadir Castilho. A concepção freireana como aporte para formação permanente de professores da EJA. Revista e-Curriculum, São Paulo, v.14, n.01, p. 165-185, jan/mar, 2016.

DELIZOICOV, Nadir Castilho; STUANI, Geovana M.; CUNHA, Suzi L. da (Orgs.). A Atualidade das Ideias de Paulo Freire. Toledo: Editora VIVENS, 2018.

DELIZOICOV, Nadir Castilho; STUANI, Geovana Murinari; DELIZOICOV, Demétrio. Reorientação curricular na concepção freireana de educação: análises em dissertações. Revista e-Curriculum, São Paulo, v. 3, n. 11, p. 648-712, set/dez, 2013.

DELIZOICOV, Demétrio. La Educación en Ciencias y la Perspectiva de Paulo Freire. ALEXANDRIA: Revista de Educação em Ciência e Tecnologia, Florianópolis, v.1, n.2, p. 37-62, jul. 2008.

DUSSEL, Enrique. Ética da libertação na idade da globalização e exclusão. Petrópolis: Vozes, 2000.

FREIRE, Paulo. Educação na cidade. São Paulo: Cortez, 1995.

FREIRE, Paulo. Política e educação. São Paulo: Cortez Editora, 1993.

FREIRE, Paulo. Extensão ou comunicação? Rio de Janeiro: Paz e Terra, 1977.

FREIRE, Paulo. Pedagogia do oprimido. Rio de Janeiro: Paz e Terra, 1975.

FREIRE, Paulo. Educação como prática de liberdade. Rio de Janeiro: Paz e Terra, 1968.

GIRON, Graziela Rossetto. A Política educacional em Caxias do Sul no governo da Administração Popular e a formação continuada de professores (1997-2004). Dissertação (mestrado) Programa de Pósgraduação em Educação, Universidade do Vale do Rio dos Sinos (UNISINOS), São Leopoldo, 2007.

GROSCH, Maria Selma. Formação continuada de professores na rede municipal de ensino de Blumenau: a escola de formação permanente Paulo Freire - EFPPF (1997-2000). Tese (doutorado) Programa de Pós-graduação em Educação, Universidade Federal de Santa Catarina, Florianópolis, 2011. 
MOLINA, Mônica Castagna. Licenciaturas em Educação do Campo e o Ensino em Ciências Naturais: Desafios à promoção do Trabalho Docente Interdisciplinar. Brasília: Editora Universidade de Brasília, 2017. v. II.

PEIXOTO, Leticia Sardinha et al. Educação permanente, continuada e em serviço: desvendando seus conceitos. Enfermeria Global, Murcia, n. 29, p. 324-339, 2013.

PERNAMBUCO, Marta Maria Castanho. Educação e escola como movimento. Tese (doutorado) Programa de Pós-graduação em Educação, Universidade de São Paulo, São Paulo, 1994.

PINTO, Alexandre Saul. Para mudar a prática de formação continuada de educadores: uma pesquisa inspirada no referencial teórico-metodológico de Paulo Freire. Tese (doutorado) - Programa de Pósgraduação em educação, PUC/SP, São Paulo, 2015.

PONTUSCHKA, Nídia Nacib. (org.) Ousadia no diálogo - Interdisciplinaridade na escola pública. São Paulo: Edições Loyola, 1993.

PORTO, Rita de Cassia Cavalcanti; LIMA, Taissa Santos de. O legado de Paulo Freire para a formação permanente: uma leitura crítica das dissertações e teses sobre a formação de professores. Revista e-Curriculum, São Paulo, v. 14, n. 01, p. 186-210, 2016.

SAUL, Ana Maria. Paulo Freire na atualidade: legado e reinvenção. Revista e-Curriculum, São Paulo, v.14, n.1, p. 9-34, jan/mar. 2016.

SAUL, Ana Maria. Políticas e práticas educativas inspiradas no pensamento de Paulo Freire: pesquisando diferentes contextos. Currículo sem Fronteiras, [online], v. 14, n. 3, p. 129-142, 2014.

SAUL, Ana Maria. O pensamento de Paulo Freire na educação brasileira: análise de sistemas de ensino a partir de 1990. Currículo sem Fronteiras, [online], v. 12, n. 3, p. 37-56, 2012.

SAUL, Ana Maria. A construção do currículo na teoria e prática de Paulo Freire. In: APPLE, Michael W.; NÓVOA, António. (org.). Paulo Freire: política e pedagogia. Porto, Porto Editora, 1998.

SAUL, Ana Maria. Formação permanente de educadores na cidade de São Paulo. ANDE, Associação Nacional de Educação. Ano 12, n. 19, 3ª̣ ed. 1993.

SAUL, Ana Maria; SILVA, Antonio Fernando Gouvêa da. Políticas de Currículo: Novos Olhares.

Educação, São Paulo, v. 04, p. 54-61, 2010.

SAUL, Ana Maria.; SILVA, Antonio Fernando Gouvêa da. O Legado de Paulo Freire para as políticas de currículo e para a formação de educadores no Brasil. Revista Brasileira de Estudos Pedagógicos, Brasília, v. 90, n. 224, p. 223-244, jan/abr. 2009.

SILVA, Antonio Fernando Gouvêa da. Das falas significativas às práticas contextualizadas: a construção do currículo na perspectiva crítica e popular. Tese (doutorado) - Programa de Pós-graduação em educação, PUC/SP, São Paulo, 2004.

SILVA, Antonio Fernando Gouvêa da. O Currículo na Práxis da Educação Popular: Projeto Pedagógico Interdisciplinar - Tema Gerador / Rede Temática. Caderno Pedagógico Estado do Rio Grande do Sul, Porto Alegre, 2002.

SILVA, Antonio Fernando Gouvêa da. Política Educacional e Construção da Cidadania. In.: SILVA, Luiz Heron da. Reestruturação Curricular: Novos Mapas Culturais, Novas Perspectivas Educacionais. Porto Alegre: Editora Sulina, 1996.

TORRES, Carlos Alberto; O' CADIZ, Maria del Pilar; WONG, Pia Lindquist. Educação e democracia - a práxis de Paulo Freire em São Paulo. São Paulo: Cortez/Instituto Paulo Freire, 2002. 
VIEIRA, Sônia Regina. Formação permanente de educadores na perspectiva freireana: um olhar sobre a experiência de Diadema. Dissertação (Mestrado) Programa de Pós-graduação em Educação: Currículo Pontifícia Universidade de São Paulo, São Paulo, 2008.

WATANABE, Gisele. (Org.) Educação Científica Freireana na Escola. São Paulo: Editora Livraria da Física, 2019.

\section{Referências dos documentos}

ESTADO DO RIO GRANDE DO SUL-RS/SEE. Constituinte escolar: construção da escola democrática e popular. Conferência estadual da educação. Porto Alegre, agosto, 2000.

PREFEITURA MUNICIPAL DE ANGRA DOS REIS-RJ/SME. Nova Qualidade do Ensino, Movimento de Reorientação Curricular, 1995.

PREFEITURA MUNICIPAL DE ANGRA DOS REIS-RJ/SME. Nova Qualidade do Ensino, Movimento de Reorientação Curricular (Documentos 2 e 3), 1996.

PREFEITURA MUNICIPAL DE CAXIAS DO SUL-RS/SMED. Plano Municipal de Educação: princípios gerais. 1999.

PREFEITURA MUNICIPAL DE CHAPECÓ-SC/SMEC. Trabalhador fazendo história. 2001.

PREFEITURA MUNICIPAL DE CHAPECÓ-SC/SMEC. Educação de Jovens e Adultos (Revista n. 1), 1998.

PREFEITURA MUNICIPAL DE CRICIÚMA-SC/SME. Programa de Educação de Jovens e Adultos (PROEJA). Nossas práticas, nossa história. Março, SME, 2003.

PREFEITURA MUNICIPAL DE ESTEIO-RS/SMEE. Aprender é movimento. Julho, 2003.

PREFEITURA MUNICIPAL DE GRAVATAÍ-RS/SMEC. 1998: ano da reorientação curricular. Revista da SMEC (Ano I, nำ1), 1998.

PREFEITURA MUNICIPAL DE MACEIÓ-AL/SMED. Departamento de Educação de Jovens e Adultos (DEJA). $4^{\circ}$ Caderno: produções coletivas. Construindo a cidadania: uma experiência em processo. Maceió, SEMED, 2001.

PREFEITURA MUNICIPAL DE PORTO ALEGRE-RS/SMED. Escola cidadã: construindo sua identidade. Revista Paixão de Aprender. Número 9. Princípios da Escola Cidadã. (Projeto Constituinte Escolar). Porto Alegre, 1995.

PREFEITURA MUNICIPAL DE PORTO ALEGRE-RS/SMED. A experiência da Escola Neuza Brizola na concretização da escola cidadã. Texto coletivo elaborado pelas professoras da Escola Municipal Neuza Goulart Brizola. Escolas por Ciclos de Formação, 1996.

PREFEITURA MUNICIPAL DE SÃO PAULO-SP/SME. Temas geradores e construção do programa. Caderno de Formação nº 3, 1991.

PREFEITURA MUNICIPAL DE SÃO PAULO-SP/SME. Movimento de Reorientação Curricular. Caderno de Relatos de Práticas, 1992a.

PREFEITURA MUNICIPAL DE SÃO PAULO-SP/SME. Movimento Reorientação Curricular: Ciências. Visão da Área. Documento: 5. 1992b. 